\title{
DETERMINATION OF THE MEAN NUMBER OF BONDS PER SNOW GRAIN AND OF THE DEPENDENGE OF THE TENSILE STRENGTH OF SNOW ON STEREOLOGIGAL PARAMETERS
}

\author{
By H. Gubler
}

(Eidg. Institut für Schnee- und Lawinenforschung, 7260 Weissfluhjoch/Davos, Switzerland)

\begin{abstract}
A theoretical density distribution of the number of bonds per grain as a function of the mean number of bonds per grain is derived from the assumption of randomness and isotropy of grain and grainbond location and orientation. The knowledge of the theoretical density distribution allows the determination of the effective distribution parameters from section planes or thin sections. The concept of the fundamental unit to describe the strength of snow is introduced. Structural parameters developed on the basis of the fundamental units show improved correlations with the tensile strength.

RÉsumé. Dérivation du nombre de liaisons par grain de neige et de la corrélation entre la résistance à la traction et des paramètres stéréologiques. La répartition en densité des nombres de liaisons par grain est dérivée en fonction du nombre moyen de liaisons par grain, en supposant l'isotropie des directions de ces liaisons. La notion de cette fonction (de répartition en densité) permet d'évaluer les paramètres effectifs de répartition des analyses de sections. L'idée des unités élémentaires est introduite pour décrire la résistance de la neige. Les paramètres de structure qui sont définis à l'aide des unités élémentaires semblant être en bonne corrélation avec la résistance à la traction.

Zusammenfassung. Bestimmung der mittleren Anzahl Bindungen pro Schneekorn und der Abhängigkeit der Zugfestigkeit von Schnee von stereologischen Parametern. Aufgrund der Voraussetzung der räumlichen Isotropie der Bindungsrichtungen wird die Dichteverteilung der Koordinationszahlen als Funktion der mittleren Koordinationszahl abgeleitet. Die Kenntnis der Dichteverteilungsfunktion erlaubt die Bestimmung der effektiven Verteilungsparameter aus Schnittanalysen. Das Konzept der Elementareinheit zur Beschreibung der Festigkeit von Schnee wird eingeführt. Mit Hilfe der Elementareinheiten definierte Strukturparameter zeigen eine gute Korrelation mit der Zugfestigkeit.
\end{abstract}

\section{INTRODUCTION}

In various papers (Ballard, I965; Hobbs, I965; Keeler, I969; St. Lawrence, [1975]; $\mathrm{Kry}, \mathrm{I} 975[\mathrm{~b}])$ it is shown that the mechanical properties of snow are essentially determined by the type of bonds between the ice grains of the snow structure. This report investigates the dependence of the ductile* strength of a snow sample on the arrangement of the bonds in the snow structure. The stereological and geometrical parameters were determined from colored section planes as described by Kry (1975[a]). To be able to perform the tests on homogeneous snow, the samples were prepared as described by Gubler ([1975]). For the tensile strength tests the well-known centrifugal technique was used.

\section{Definition of The "Fundamental Unit"}

Snow can be considered as a network of grains connected by ice bonds. At least in lowdensity snow, no structural order or periodicity exists. Nevertheless the models discussed in this paper propose that the mechanical properties of snow can be traced back to the features of fundamental units. Kry (r975[b]) developed semi-quantitative calculations on the basis of the concept of the fundamental unit to explain the observed variation in the viscoelastic properties of snow. The basic features of the fundamental units (Gubler, 1978) are:

a. The snow structure may be subdivided into fundamental units.

b. Each fundamental unit acts as a force-conducting link in the snow structure.

c. As regards their positions, the properties of the fundamental units are distributed at random.

* The characterization "ductile" is used to describe any type of fracture which is not entirely brittle. 
d. The properties (e.g. strength) of the fundamental units are defined by distribution functions.

e. The mechanical properties of a distinct snow may be derived as a function of the density distribution of the corresponding features among the fundamental units, of the number density of the fundamental units, and of the strain-rate.

A chain, defined as a series of a single force-bearing grains is proposed to be the basic element of a fundamental unit. The chain is terminated either by a structural element of higher connectivity or by a branch to other chains. The effective coordination number (number of contacts) of a chain grain is $n_{3} \mathrm{e}=2$. A bond between two ice grains is denoted as effective if the bond bears a force which can be traced back to the external stresses acting on the sample. The remaining grains of the structure with coordination numbers not equal to 2 are thought to be distributed uniformly on these basic elements. We distinguish three types of grains with contact numbers not equal to 2 : Grains with a coordination number $n_{3}=1$ (end grains), grains with $n_{3}>2$ at the end of a chain (link grains) and grains with $n_{3}>2$ which are not in contact with a chain (mesh grains). Therefore the fundamental unit consists of a chain as the basic element, the corresponding link grains, end grains and mesh grains (Fig. I).

In the following sections the distribution of the coordination numbers $n_{3}$, the mean length of the basic elements, and the magnitude of the fundamental units will be determined.

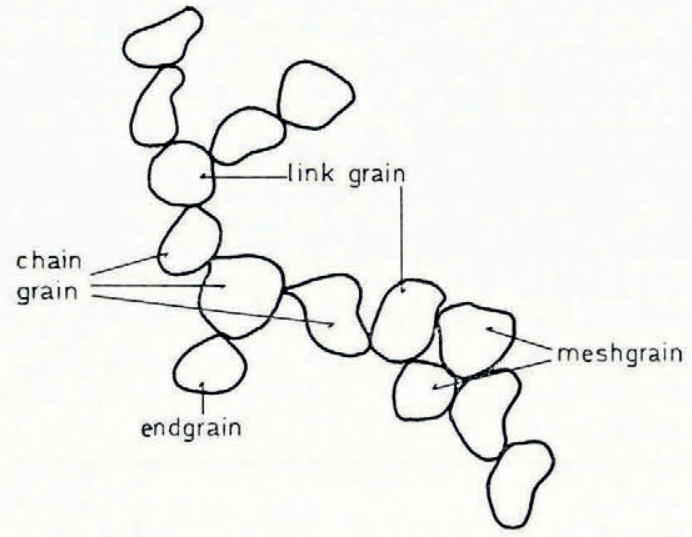

Fig. I. Definition of a chain.

\section{Parameters to be determined from section planes}

The following values were measured by a semi-automatic counting method:

$P_{\mathrm{p}}$ : Point density. A network of points is arranged uniformly over the section area of the microstructure. $P_{\mathrm{p}}$ is defined as the ratio of the number of points that fall inside the grains to the total number of points of the network.

$P_{\mathrm{L}}$ : A linear test array is applied to the section area of the microstructure. $P_{\mathrm{L}}$ is defined as the number of intersections of the test lines with the grain boundaries per unit length of the test line.

The next three values were determined by simple counting or by length measurements in the section planes:

$\mathcal{N}_{\mathrm{A}} \mathrm{B}\left(n_{2}\right)$ : Number of grains per unit area with $n_{2}$ bonds cut by the section plane.

$\mathcal{N}_{\mathrm{A}}$ : Total number of grains per unit area of the section plane.

$d_{2}$ : Length of the line representing a grain bond in the section plane. 


\section{DEFINITION OF GRAIN-BOND}

A grain bond is defined as the plane surface of minimum area situated in the neck region of two linked grains. The grain-bond area has the shape of a disk (Kry, I975[a]). If a grain bond is cut by a section plane it will appear as one or two parallel straight lines connecting two opposite necks of the ice. In the evaluation of the section planes every configuration characterized by two obvious necks exactly facing each other has been considered as a bond or a weak region of the structure.

\section{TheORETICAL DERIVATION OF THE DENSITY DISTRIBUTION OF THE COORDINATION NUMBERS}

Statistical reasons impede a direct determination of the density distribution of the coordination numbers $f_{3}\left(n_{3}\right)$ from the measured distribution $f_{2}$ of the numbers of bonds per grain $n_{2}$ cut by a section plane independent of further assumptions. The probability of a section plane cutting simultaneously several bonds belonging to the same grain is quite low. For an evaluation of 300 to 500 grains per sample cut by section planes, the standard deviation for $n_{2}>2$ is almost equal to the corresponding mean value of $n_{2}$. The evaluation of larger section planes is very time consuming.

A theoretical determination of the density distribution $f_{3}$ of the coordination numbers $n_{3}$ as a function of the mean coordination number $\bar{n}_{3}$ allows us to deduce the corresponding distribution $f_{2}$ of the numbers of bonds per grain $n_{2}$ cut by a section plane. A search for the best correspondence of the measured distributions $f_{2}$ with the theoretically deduced $f_{2}$ as a function of $\bar{n}_{3}$ and a second distribution parameter yields a possibility for an estimation of $\bar{n}_{3}$ even for inaccurately measured values for $f_{2}\left(n_{2}>2\right)$.

A theoretical derivation of the type of density distribution $f_{3}\left(n_{3}\right)$ is possible with the assumption of randomness and isotropy of grain-bond location and orientation. Kry (1975[b]) has shown that this condition is satisfied within an error of $\pm 10 \%$ even after $30 \%$ uniaxial plastic deformation of the sample.

For each grain we define a vector $\mathbf{k}$ of a magnitude $n^{i}$ with $n$ equal to the number of bonds belonging to the grain and whose direction is given by the mean bond direction relative to the centre of gravity of the grain. $i$ is a free parameter of the resulting distribution function. As a consequence of the isotropy of the bond directions, the probability $\mathrm{d} W$ that any vector ends in the interval between $\mathbf{k}$ and $\mathbf{k}+\mathrm{d} \mathbf{k}$ is equal to the product of the independent probabilities that the components of the vector with reference to an arbitrary set of basic vectors end in the corresponding intervals of the components.

$$
\begin{aligned}
\mathrm{d} W(\mathbf{k}) & =F(k) \mathrm{d} k_{1} \mathrm{~d} k_{2} \mathrm{~d} k_{3} \\
& =f_{1}\left(k_{1}\right) f_{2}\left(k_{2}\right) f_{3}\left(k_{3}\right) \mathrm{d} k_{1} \mathrm{~d} k_{2} \mathrm{~d} k_{3},
\end{aligned}
$$

where $k_{e}$ are the components of the vector $\mathbf{k}$

$$
k=\left(k_{1}^{2}+k_{2}^{2}+k_{3}^{2}\right)^{\frac{1}{2}} \equiv n^{i} .
$$

Differentiating Equation (I) with respect to the component $k_{\mathrm{I}}$ it ${ }_{\mathbf{L}}^{-}$follows that

$$
\begin{aligned}
\frac{\mathrm{I}}{F(k)} \frac{\mathrm{d} F(k)}{\mathrm{d} k} \frac{\mathrm{d} k}{\mathrm{~d} k_{\mathrm{I}}} & =\frac{\mathrm{d} f_{\mathrm{I}}}{\mathrm{d} k_{\mathrm{I}}} \frac{F_{\mathrm{I}}}{f_{\mathrm{I}}}, \\
\frac{\mathrm{d} k}{\mathrm{~d} k_{\mathrm{I}}} & =2 i \frac{n_{\mathrm{I}}^{i}}{n^{i}} .
\end{aligned}
$$

Equation (4) inserted in Equation (3) yields

$$
\frac{\mathrm{I}}{F\left(n^{i}\right)} \frac{\mathrm{d} F}{\mathrm{~d}\left(n^{i}\right)} \frac{\mathrm{I}}{n^{i}}=\frac{\mathrm{I}}{f_{\mathrm{I}}} \frac{\mathrm{d} f_{\mathrm{I}}}{\mathrm{d}\left(n_{1}{ }^{i}\right)} \frac{\mathrm{I}}{2 i n_{\mathrm{I}}{ }^{i}} .
$$


From the fact that the left-hand side of Equation (5) is only a function of $n$ whereas the righthand side is only a function of $n_{\mathrm{I}}$ it follows that both sides have to be equal to a common constant $-\alpha$ :

$$
\frac{\mathrm{d} F\left(n^{i}\right)}{F\left(n^{i}\right)}=-2 i \alpha n^{2 i-1} \mathrm{~d} n .
$$

The integration of Equation (6) yields

$$
F(k)=F\left(n^{i}\right)=C \exp \left(-\alpha n^{2 i}\right) .
$$

The probability $W(n)$ of finding a grain with a coordination number between $n$ and $n+\mathrm{d} n$ independent of the mean bond direction is given by the integration of $F\left(n^{i}\right)$ over all directions.

$$
\begin{aligned}
\mathrm{d} W\left(n^{i}\right) & =C^{\prime} \exp \left(-\alpha n^{2 i}\right) n^{2 i} \mathrm{~d}\left(n^{i}\right), \\
f_{3}\left(n_{3}\right) & =\frac{\mathrm{d} W(n)}{\mathrm{d} n}=\mathcal{N} n^{3 i-1} \exp \left(-\alpha n^{2 i}\right),
\end{aligned}
$$

where $C, C^{\prime}$, and $\mathcal{N}$ are constants.

The normalizing constant $\mathcal{N}(i)$ and the constant $\alpha(i)$ are given by

$$
\begin{aligned}
& \mathcal{N}=4 i \frac{\alpha^{\frac{3}{2}}}{\pi^{\frac{1}{2}}}, \\
& \alpha=\left[\frac{2}{\pi^{\frac{1}{2}}} \frac{\mathrm{I}}{\bar{n}_{3}} \Gamma\left(\frac{3}{2}+\frac{\mathrm{I}}{2 i}\right)\right]^{2 i} .
\end{aligned}
$$

$\Gamma$ is the gamma function and $\bar{n}_{3}$ the mean coordination number.

DERIVATION OF THE DIsTRIBUtion OF THE NUMBERS OF BONDS PER GRAIN $f_{2}\left(n_{2}\right)$ CUT BY SECTION PLANES

$p$ is defined as the probability that, if a grain with a coordination number $n_{3}=\mathrm{I}$ is cut by a section plane, its bond also appears in the section plane. A bond appears in a section plane only if the centre of the bond-disk falls into a band of width $b$ whose centre line is identical with the intersecting line of the section plane with the grain (Fig. 2). The bond areas are assumed to be random and isotropically distributed on the grain surface. They are also considered to be small compared to the grain surface area as well as compared to the bond area. From these conditions it follows that the probability $P_{l}{ }^{k}$ of finding simultaneously $l$ bonds of a grain with a coordination number $k$ in the above-defined band is

$$
P_{l}^{k}=\left(\begin{array}{l}
k \\
l
\end{array}\right) p^{l}(\mathrm{I}-p)^{k-l} \text {. }
$$

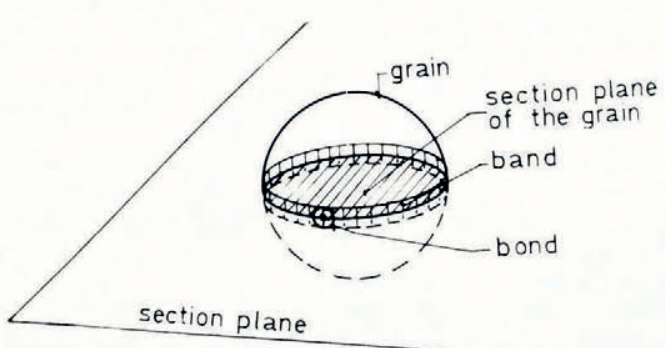

Fig. 2. Sketch of a grain cut by a section plane. 
If the subscript $k$ is summed from unity to $12\left(n_{3}=12\right.$ corresponds to the coordination number in a close-packed structure of balls) we get the density distribution of the number of bonds per grain cut by a section plane $f_{2}(l)$ :

$$
f_{2}(l)=\sum_{k=1}^{12} P_{l^{k}} f(k)=\sum_{k=1}^{12}\left(\begin{array}{l}
k \\
l
\end{array}\right) p^{l}(\mathrm{I}-p)^{k-l} f_{3}(k) .
$$

\section{Estimation of THE PROBABILITy $p$}

The probability $p$ that a grain with $n_{3}=\mathrm{I}$ and its bond are cut simultaneously by a section plane is approximately given by the ratio of the mean area $\bar{s}_{\mathrm{B}}$ of the band defined above (band-width $b$ ) to the mean grain surface area $\bar{s}_{k} . p$ is a function of the ratio of the mean diameter of the bond disks to the mean grain diameter, of the corresponding distribution functions as well as of the grain shape.

$$
p=\bar{s}_{\mathbf{B}} / \bar{s}_{k} \text {. }
$$

The specific grain surface area (area per unit volume) is independent of the grain shape (Underwood, I970)

$$
S_{\mathrm{v}}={ }_{2} P_{\mathrm{L}} \text {. }
$$

The number of grains per unit volume $\mathcal{N}_{\mathrm{v}}$ depends on the grain shape (Underwood, 1970)

$$
\mathcal{N}_{\mathrm{v}}=C^{\prime} \mathcal{N}_{\mathrm{A}}{ }^{2} / P_{\mathrm{L}}
$$

where $C^{\prime}$ is a function of the shape of the grains.

Therefore $\bar{s}_{k}$ is given by

$$
\bar{s}_{k}=\frac{{ }_{2} P_{\mathrm{L}^{2}}}{C^{\prime} \mathcal{N}_{\mathrm{A}}{ }^{2}} .
$$

The mean length of the centre line of the band which is identical with the intersecting line of the section plane with the grain is

$$
\begin{aligned}
L_{k} & =\frac{1}{2} \pi P_{\mathrm{L}} / \mathcal{N}_{\mathrm{A}}, \\
\bar{s}_{\mathrm{B}} & =\frac{1}{2} \pi P_{\mathrm{L}} b / \mathcal{N}_{\mathrm{A}} .
\end{aligned}
$$

The mean band width $b$ can be deduced from the mean intersection length of the bonds $d_{2}$ and the corresponding mean bond-disk radius:

$$
b=2\left[\frac{2}{r_{3}}-\left(\frac{d_{2}}{2}\right)^{2}\right]^{\frac{1}{2}} .
$$

The mean three-dimensional radius of the grain bonds $\bar{r}_{3}$ is given by the harmonic mean of the length of the lines representing grain bonds in the section plane $d_{2}$ (Underwood, 1970)

$$
\begin{aligned}
\bar{E} & =\overline{\left(\mathrm{I} / d_{2}\right)}, \\
\bar{r}_{3} & =\pi / 4 E, \\
b & =\bar{d}_{3}\left[\mathrm{I}-(\pi / 8)^{2}\left(\bar{E} d_{2}\right)^{2}\right]^{\frac{1}{2}},
\end{aligned}
$$

where $\left(E d_{2}\right)$ is a function of the assymetric density distribution of the measured $d_{2}$.

From the measurements, the value of the square root in Equation (23) is

$$
b=0.88 \bar{d}_{3} \text {. }
$$


The probability $p$ is

$$
p=\frac{1}{4} C \pi \mathcal{N}_{\mathrm{A}} \bar{d}_{3} / P_{\mathrm{L}}
$$

For rounded grains $C^{\prime}$ is about $\mathrm{I} \cdot 5, C \approx \mathrm{I} \cdot 3$.

\section{Estimation OF THE MEAN LENGTH OF THE BASIG GHAINS}

We assume that in medium-density snow the end grains are randomly distributed on all free bonds of grains with $n_{3} \geqslant 2$. The probability that any bond of a grain with $n_{3} \geqslant 2$ leads to an end grain is:

$$
W_{\mathrm{I}}=\frac{f_{3}\left(n_{3}=\mathrm{I}\right)}{\sum_{n_{3}=2}^{12}\left(n_{3}-\mathrm{I}\right) f_{3}\left(n_{3}\right)} .
$$

The probability that a grain has two effective bonds is

$$
f_{3}\left(n_{3} \mathrm{e}=2\right)=f_{3}(2)\left(\mathrm{I}-W_{\mathrm{I}}\right)+\sum_{n=3}^{12}(n-\mathrm{I}) W_{\mathrm{I}}^{(n-2)} f_{3}^{(n)}
$$

For the probability to find a chain composed of $k$ chain-grains we get approximately:

$$
\begin{aligned}
W_{2} k & =\prod_{m=0}^{k-1} \frac{\mathcal{N}_{\mathrm{v}} f_{3}\left(n_{3} \mathrm{e}=2\right)-m}{\left[\sum_{n=1}^{\mathrm{I} 2} \mathcal{N}_{\mathrm{v}} f_{3}\left(n_{3}\right)\right]-m} \\
& \approx\left[\frac{f_{3}\left(n_{3} \mathrm{e}=2\right)}{\sum_{n_{3}=1}^{\mathrm{I} 2} f\left(n_{3}\right)}\right]^{k} \equiv R_{2}^{k} .
\end{aligned}
$$

Therefore the mean number of grains per chain is

$$
k_{2}=\frac{\sum_{k=1}^{\infty} k R_{2} k}{\sum_{k=1}^{\infty} R_{2} k}=\frac{1}{1-R_{2}},
$$

with a variance of

$$
\sigma \bar{k}_{2}^{2}=\frac{2+R_{2}}{\left(\mathrm{I}-R_{2}\right)^{2}} .
$$

The number of chains per unit volume which is equivalent to the specific number of fundamental units is

$$
E_{\mathrm{v}}=\frac{\mathcal{N}_{\mathrm{v}} f_{3}\left(n_{3} \mathrm{e}=2\right)}{\bar{k}_{2}} .
$$

The specific number of grains is

$$
\mathcal{N}_{\mathrm{E}}=\mathcal{N}_{\mathrm{v}} / E_{\mathrm{v}}
$$

Additionally we define the mesh-parameter as the ratio of the effective (stressed) grains which do not belong to a chain to the mean number of grains per chain $\bar{k}_{2}$.

$$
P_{\mathrm{v}}=\frac{\mathcal{N}_{\mathrm{E}}-\bar{k}_{2}-f_{3}\left(n_{3}=\mathrm{I}\right) \mathcal{N}_{\mathrm{E}}}{\bar{k}_{2}} .
$$


To be able to investigate the correlations between the structural parameters defined above and the strength of the fundamental structures, a reduced strength index $\sigma_{R}$ for the fundamental units as a function of snow strength has to be defined:

$$
\sigma_{\mathrm{R}}=\frac{\sigma_{\mathrm{T}} r_{\mathrm{o}}^{2}}{E_{\mathrm{v}}{ }^{\frac{2}{2}} r_{\mathrm{b}^{2}}}, \quad r_{0}=\mathrm{IO}^{-5} \mathrm{~m} .
$$

The reasons for this type of normalization are: (I) The ductile strength (Gubler, 1978) is a function of the number of fundamental units per unit area. (2) The correlation between structural parameters and strength should hold independently of the mean bond area.

\section{Evaluation of THE EXPERIMENTAL DATA}

Determination of $f_{2}\left(\bar{n}_{3}, p\right)$

Fourteen data sets of snow samples with densities between $170 \mathrm{~kg} / \mathrm{m}^{3}$ and $370 \mathrm{~kg} / \mathrm{m}^{3}$ and tensile strengths from $6000 \mathrm{~Pa}$ to 220 ooo $\mathrm{Pa}$ have been evaluated. The relative standard deviation for the tensile strength measurements amounts to $10 \%$. The corresponding values for $P_{\mathrm{p}}$ and $P_{\mathrm{L}}$ are $5 \%$. The relative standard deviations for the bond counts are: $\mathcal{N}_{\mathrm{A}} \mathrm{B}\left(n_{2}=0\right)$ : $\pm 20 \%, \mathcal{N}_{\mathrm{A}}^{\mathrm{B}}\left(n_{2}=\mathrm{I}\right): \pm 30 \%, \mathcal{N}_{\mathrm{A}}^{\mathrm{B}}\left(n_{2}=2\right): \pm 50 \%$, and $\mathcal{N}_{\mathrm{A}} \mathrm{B}\left(n_{2}=3\right): \pm 100 \%$. A typical histogram of a measurement of the lengths $d_{2}$ of the lines representing bonds in the section

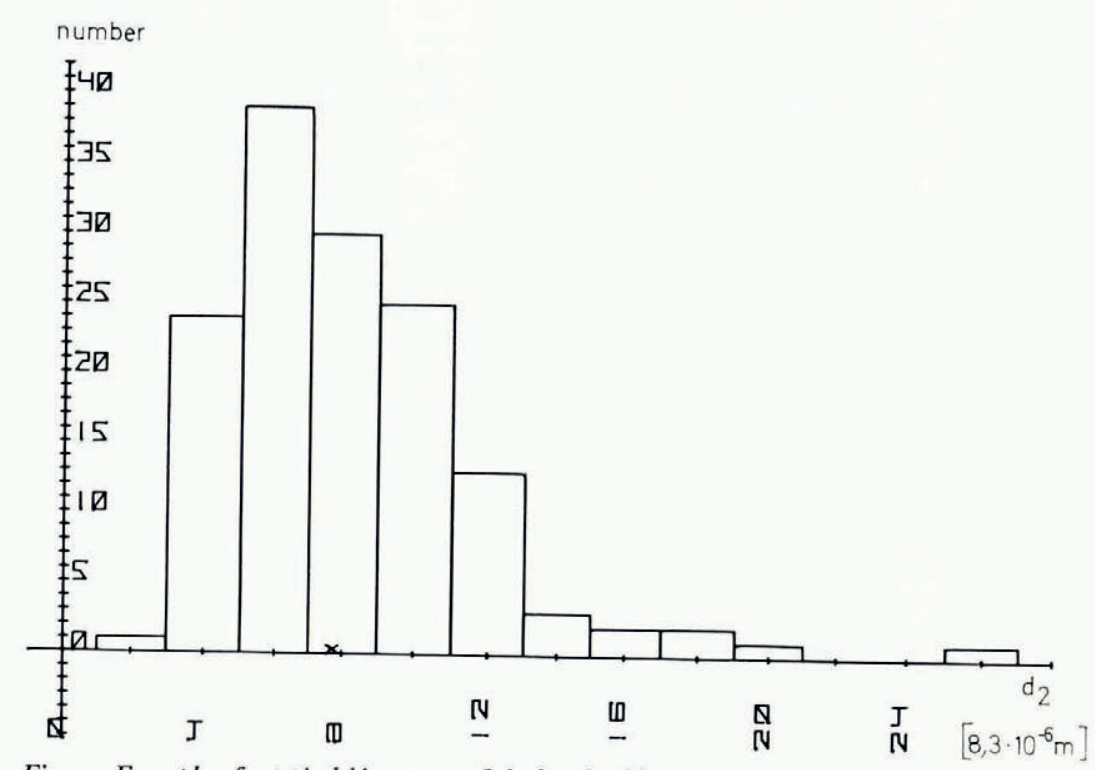

Fig. 3. Example of a typical histogram of the length of lines representing bonds in a section plane.

planes is given in Figure 3. The mean coordination numbers $\bar{n}_{3}$ of the samples and the additional parameter $i$ of the distribution function are determined by the comparison of the measured fractions $f_{2}\left(n_{2}\right)$ with the theoretically calculated fractions $f_{2}\left(n_{2}\right)$ as a function of $\bar{n}_{3}, i$, and $p$. The probability $p$ specific to the sample results from Equation (24). The mean correspondance of the calculated and the measured $f_{2}\left(n_{2}\right)$ is highest for the function type $f_{3}$ with $i=1$.5. A typical example for the determination of $\bar{n}_{3}$ is given in Figure 4 . Figure 5 shows the corresponding distribution function, and Figure 6 part of a section plane.

The specific numbers of fundamental units $E_{\mathrm{v}}$ for the samples investigated range from about $10^{8}$ to $10^{10} \mathrm{~m}^{-3}$, the specific number of grains $\mathcal{N}_{\mathrm{E}}$ from 4 to 334 and the mean number of chain grains per fundamental unit from 1.003 to 2.274 . 


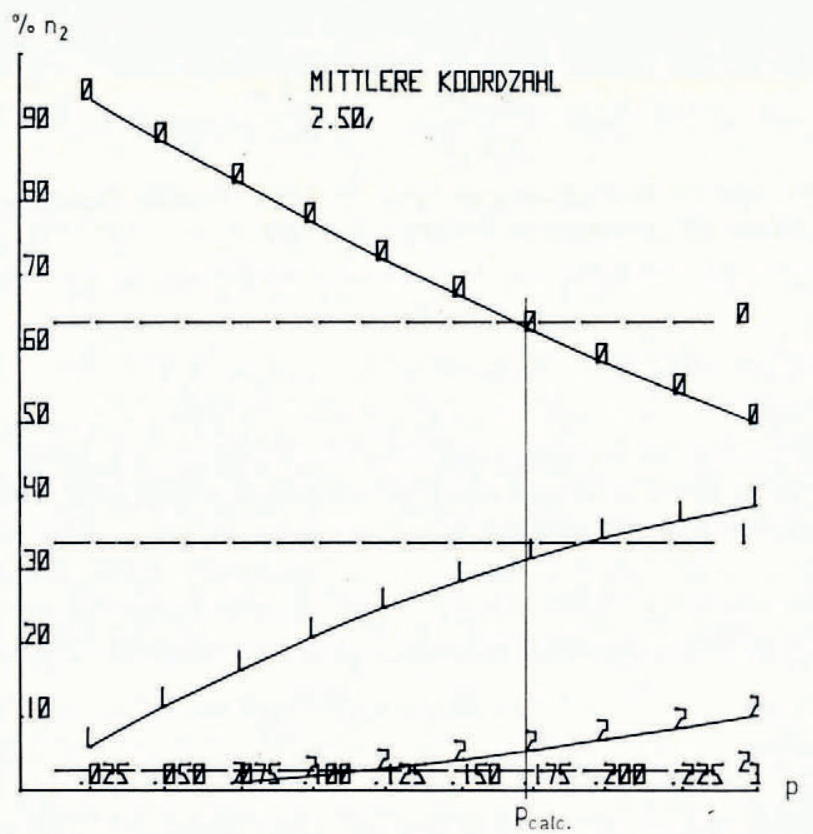

Fig. 4. Example of the determination of $\bar{n}_{3}$ by comparing the measured distributions of the $n_{2}$ with the corresponding calculated distribution for a given probability $p$.

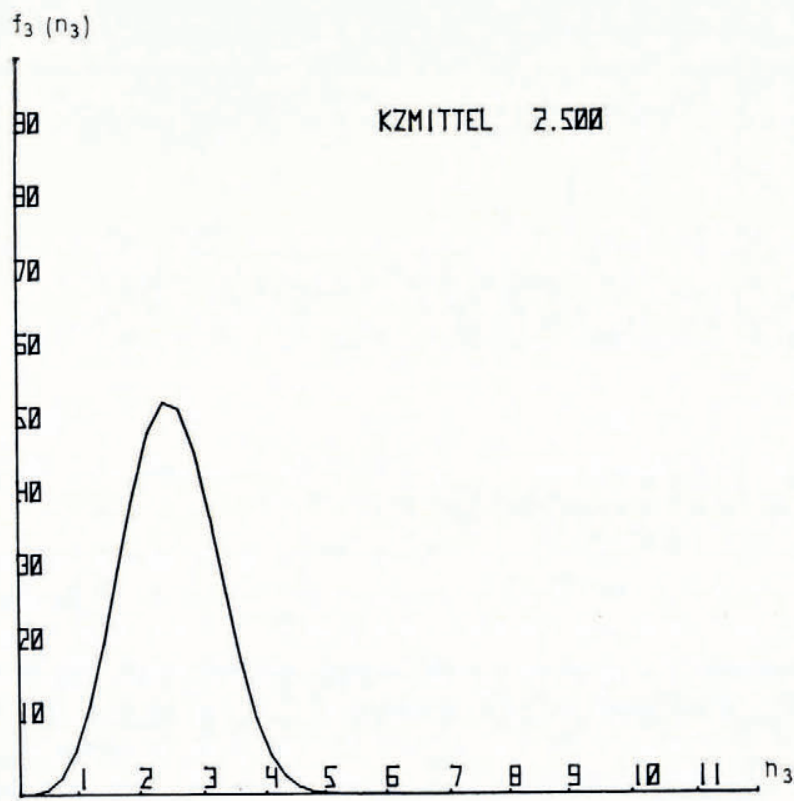

Fig. 5. Probability density $f_{3}\left(n_{3}\right) \simeq n^{3 / 2} \exp \left(-\alpha n^{3}\right)$ for $\bar{n}_{3}=2.5$. 


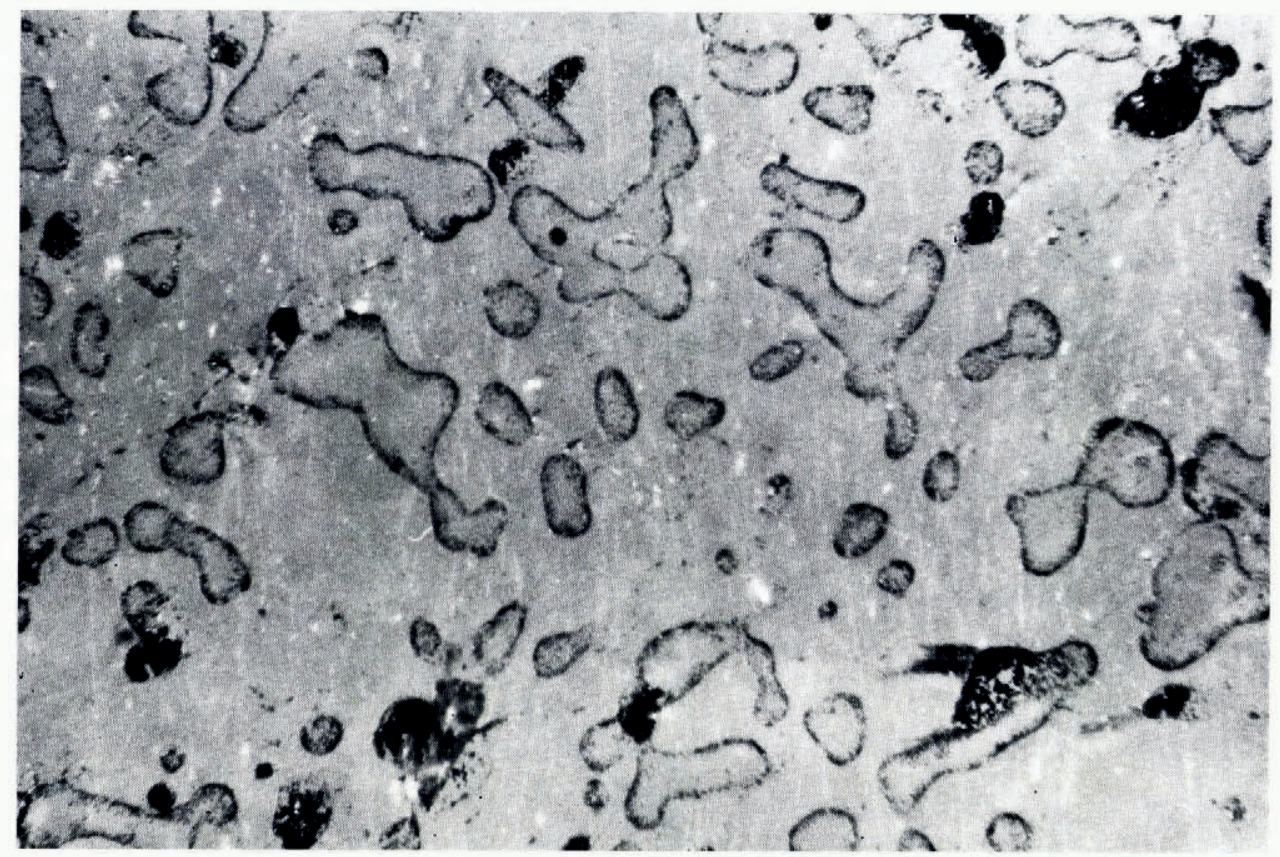

Fig. 6. Part of a section plane of a sample with $\bar{n}_{3}=2.5$.

List of the correlations investigated

$\rho_{P_{\mathbf{p}}}\left(\rho_{\mathrm{g}}\right)$ Stereologically determined density as a function of the measured density.

$\sigma_{\mathrm{T}}\left(\rho_{\mathrm{g}}\right)$ Tensile strength as a function of density $\rho_{\mathrm{g}}$.

$\sigma_{\mathrm{R}}\left(\sigma_{P_{\mathrm{p}}}\right) \quad$ Strength index as a function of $\rho_{P_{\mathrm{p}}}$.

$\bar{n}_{3}\left(\rho_{P_{\mathrm{p}}}\right) \quad$ Mean coordination number as a function of $\rho_{P_{\mathrm{p}}}$.

$\sigma_{\mathbf{R}}\left(k_{2}\right)$ Strength index as a function of the mean number of grains per chain.

$\sigma_{\mathbf{R}}\left(\bar{n}_{3}\right)$ Strength index as a function of the mean coordination number.

$\sigma_{\mathrm{R}}\left(P_{\mathrm{V}}\right)$ Strength index as a function of the mesh-parameter.

$\sigma_{\mathrm{R}}\left(\mathrm{I} /\left(\bar{k}_{2}-\mathrm{I}\right)\right)$ Strength index as a function of the reciprocal of the effective mean number of grains per chain.

In a first approximation, the correlations are assumed to be linear for the investigated ranges. The resulting correlation coefficients are given in Table I. The corresponding values for the best fits of power functions to the experimental data are given in brackets.

TABle I. Linear correlation COEFficients

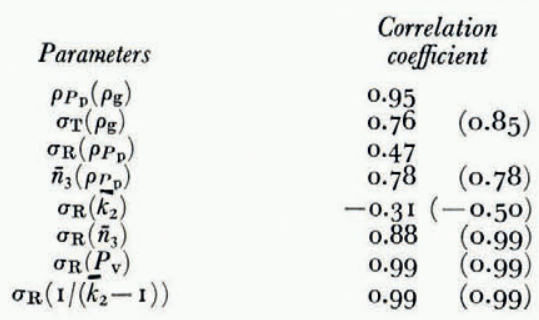




\section{Discussion of the correlations}

a. $\rho_{P_{\mathrm{p}}}\left(\rho_{\mathrm{g}}\right): \rho_{\mathrm{g}}$ is determined from the sample weight and the corresponding sample volume whereas $\rho_{P_{\mathrm{p}}}$ as a function of the point-density $P_{\mathrm{p}}$ and the density of ice. The linear correlation is almost perfect.

b. $\sigma_{\mathbf{T}}\left(\rho_{\mathrm{g}}\right)$ : This type of correlation corresponds to the usual representation of the physical properties of snow as a function of density (Fig. 7). The data split into two groups. Group I results from densified samples whereas the samples of group II have been sintered without densification. Therefore the resulting strengths are not only a function of the densities but also of structural modifications resulting from the history of deformation.

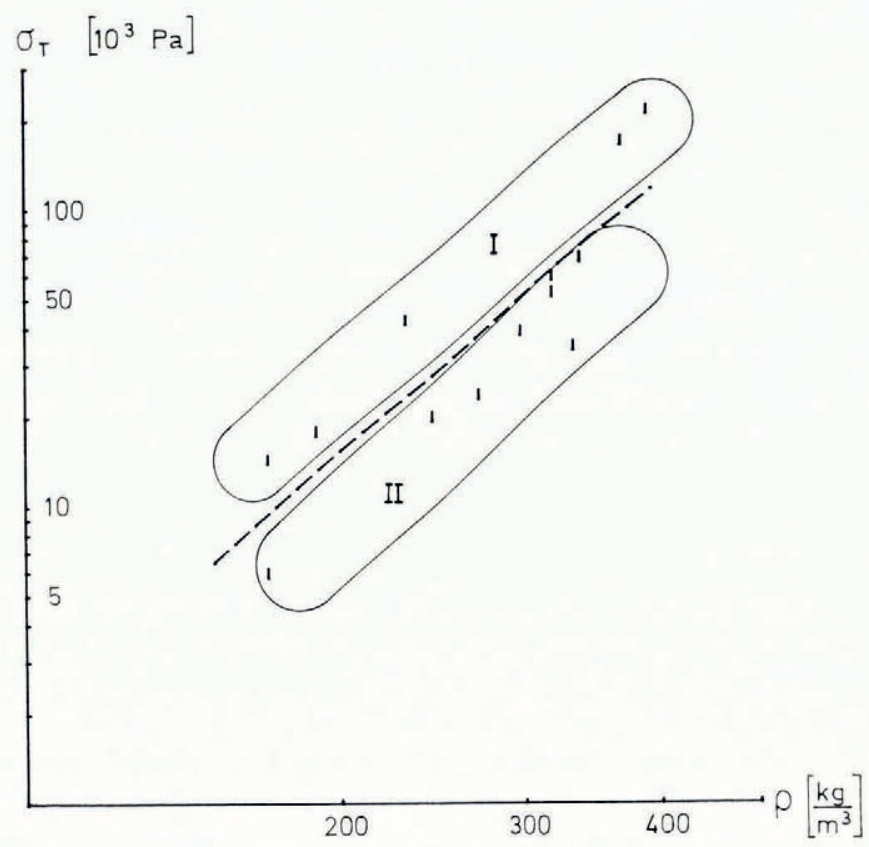

Fig. 7. Measured tensile strength as a function of sample density.

c. $\sigma_{\mathrm{R}}\left(\rho_{P \mathrm{p}}\right)$ : The correlation is expected to be weak because the strength index $\sigma_{\mathrm{R}}$ is an almost density-independent parameter.

d. $\bar{n}_{3}\left(\rho_{P}\right)$ : The mean coordination number $\bar{n}_{3}$ is expected to be essentially determined by the history of deformation. Additionally, different grain shapes may cause different densities for almost equivalent distributions of the coordination numbers. The resulting correlation coefficient sustains these assumptions.

e. $\sigma_{\mathrm{R}}\left(\bar{k}_{2}\right): \sigma_{\mathrm{R}}$ anticorrelates with the chain length. Longer chains with possibly higher eccentricities are expected to be weaker.

f. $\sigma_{\mathrm{R}}\left(\bar{n}_{3}\right)$ : A high mean number of contacts per grain allows only short chains. This fact tends to increase the mean strength of the fundamental units. A good correlation is expected. The corresponding dependence is plotted in Figure 8:

$$
\sigma_{\mathrm{R}} \approx \bar{n}^{3 \cdot 64} \text {. }
$$




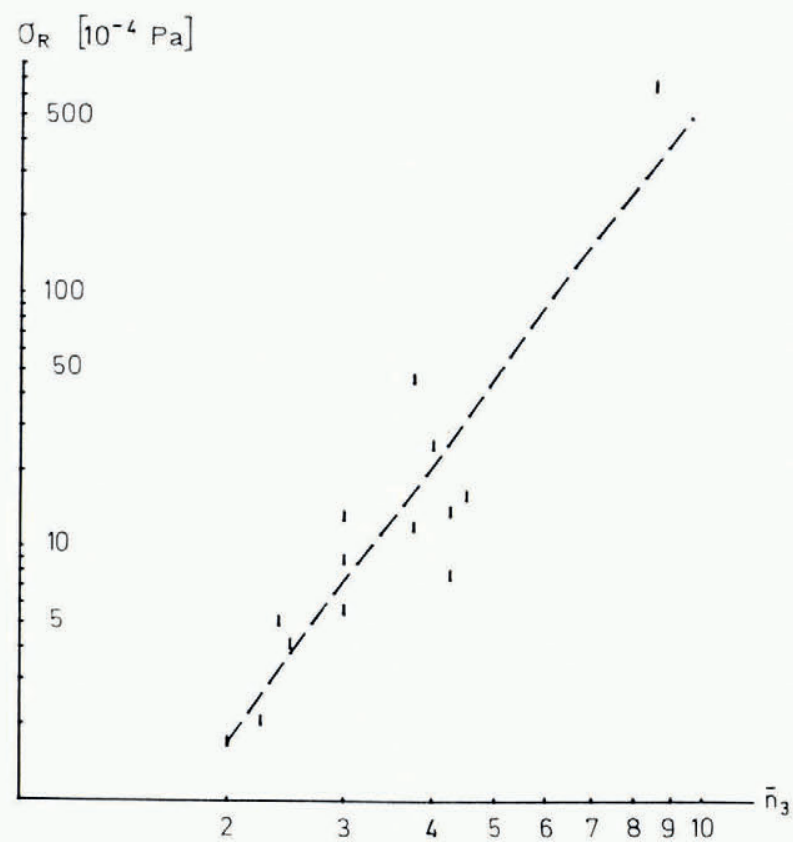

Fig. 8. Strength index $\sigma_{\mathrm{R}}$ as a function of the mean coordination number $\bar{n}_{3}$.

g. $\sigma_{\mathrm{R}}\left(P_{\mathrm{v}}\right)$ : The higher the magnitude of the mesh parameter $P_{\mathrm{v}}$ the higher is the portion of the force acting on a fundamental structure borne by multiple reinforced configurations of grains. These reinforced configurations of grains are thought to have a significantly higher strength at least at low strain-rates because relaxation processes allow an optimal rearrangement of the forces on the different structural parts. Therefore a high correlation between $\sigma_{\mathrm{R}}$ and $P_{\mathrm{v}}$ is expected.

h. $\sigma_{\mathbf{R}}\left(\mathbf{I} /\left(\bar{k}_{2}-\mathrm{I}\right)\right)$ : The mean eccentricity of the basic chains is assumed to be a monotonically increasing function $g\left(k_{2}-1\right)$ of the reduced chain length. The maximum stresses in the bonds $\sigma_{\mathrm{B}}$ of a chain increase with increasing eccentricity:

$$
\sigma_{\mathrm{B}}=\sigma_{\mathrm{R}} h\left(g\left(\bar{k}_{2}-\mathrm{I}\right)\right),
$$

where $h$ is again a monotonically increasing function. Therefore $\sigma_{\mathrm{R}}$ as a function of the bond strength $\sigma_{\mathrm{FB}}$ becomes

$$
\sigma_{\mathrm{R}}=\frac{\sigma_{\mathrm{FB}}}{h\left(g\left(\bar{k}_{2}-\mathrm{I}\right)\right.} .
$$

For these reasons a high correlation between $\sigma_{R}$ and the reciprocal of the effective mean number of grains per chain is expected.

The measurements as well as the models do not allow a prediction of the functional dependence, but already simple power functions allow a satisfactory description of $\sigma_{\mathrm{R}}$ as a function of $P_{\mathrm{V}}$ and $\mathrm{I} /\left(\bar{k}_{2}-\mathrm{I}\right)$ for the measured range of $\sigma_{\mathrm{T}}$.

$$
\begin{aligned}
& \sigma_{\mathrm{R}} \approx\left(\frac{\mathrm{I}}{\bar{k}_{2}-\mathrm{I}}\right)^{0.84} \quad \text { correlation coefficient: 0.99, } \\
& \sigma_{\mathrm{R}} \approx P_{\mathrm{v}^{0.78}} \quad \text { correlation coefficient: } 0.99 \text {. }
\end{aligned}
$$

The experimental data and the power functions are given in Figures 9 and $\mathbf{~} 0$. 


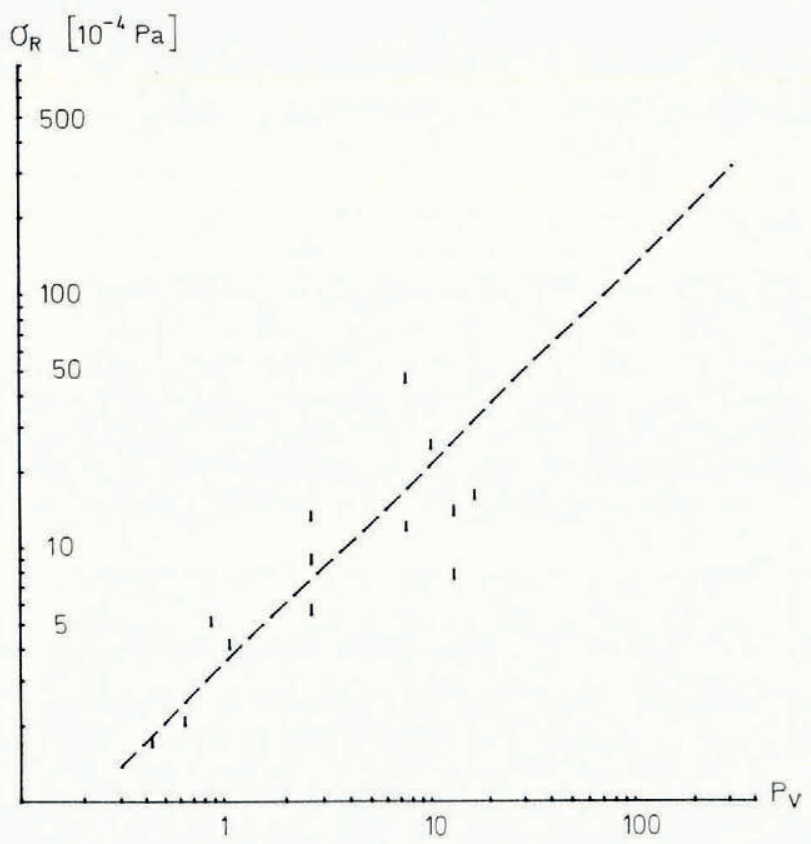

Fig. 9. Strength index $\sigma_{\mathrm{R}}$ as a function of the mesh parameter $P_{\mathbf{v}}$.

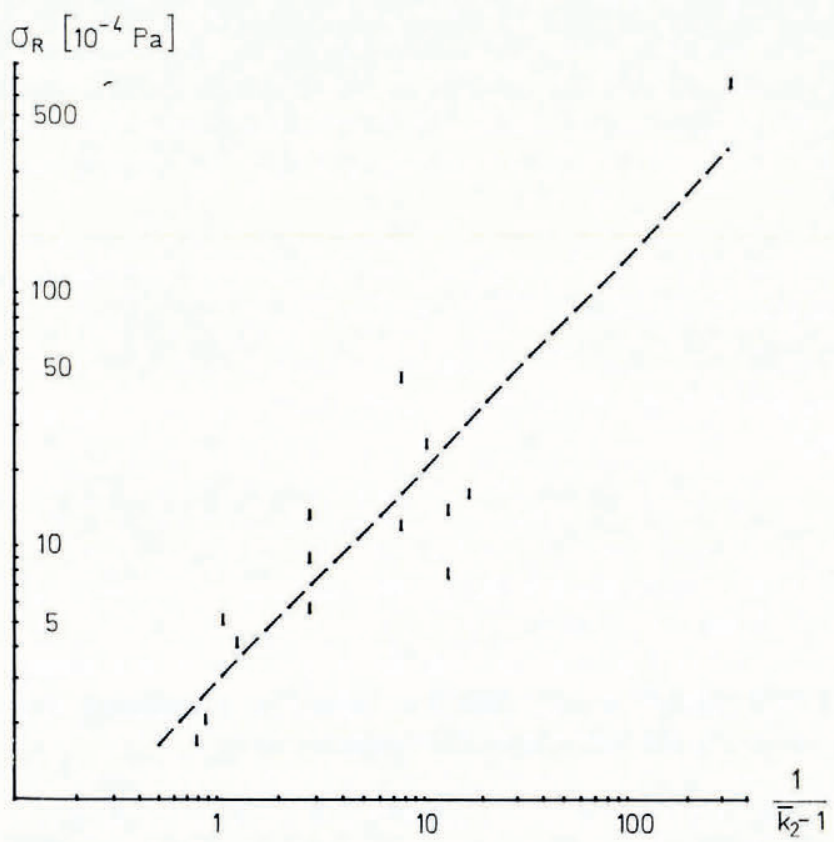

Fig. 1o. Strength index $\sigma_{\mathrm{R}}$ as a function of the mean values of the reciprocals of the reduced numbers of grains per chain. 


\section{Conclusions}

This paper shows that using simple structural parameters instead of the snow density (Fig. 7) results in significantly improved correlations with the tensile strength. For an improvement of the models, new strength measurements at constant stress or strain-rates have to be measured. In an improved model the effects of the stress rate and of the width of the distribution of strength of the fundamental units have also to be considered.

\section{Acknowledgement}

I am indebted to B. Salm, W. Good, O. Buser, and M. de Quervain for valuable discussions. MS. received 26 August 1977

\section{REFERENGES}

Ballard, G. E. H. 1965 . A theory of snow failure. U.S. Cold Regions Research and Engineering Laboratory. Research Report 137.

Fullmann, R. L. 1953. Measurement of particle sizes in opaque bodies. Fournal of Metals, Vol. 197, No. 3, p. $447-52$.

Gubler, H. [1975.] On the Rammsonde hardness equation. [Union Géodesique et Géophysique Internationale. Association Internationale des Sciences Hydrologiques. Commission des Neiges et Glaces.] Symposium. Mécanique de la neige. Actes du colloque de Grindelwald, avril 1974, p. 1 I0-21. (IAHS-AISH Publication No. I I4.)

Gubler, H. 1978. An alternate statistical interpretation of the strength of snow. Fournal of Glaciology, Vol. 20, No. 83 , p. $343-57$.

Hobbs, P. V. 1965 . The effect of time on the physical properties of deposited snow. Fournal of Geophysical Research, Vol. 7o, No. I6, p. 3903-07.

Keeler, C. M. 1969 . The growth of bonds and the increase of mechanical strength in a dry seasonal snow-pack. Journal of Glaciology, Vol. 8, No. 54, p. 441-50. Kry, P. R. $1975[\mathrm{a}]$. Quantitative stereological analysis of grain bonds in snow. Fournal of Glaciology, Vol. 14,
No. 72, p. $467-77$.

Kry, P. R. $1975[\mathrm{~b}]$. The relationship between the visco-elastic and structural properties of fine-grained snow. Journal of Glaciology, Vol. 14, No. 72, p. 479-500.

St. Lawrence, W. [1975.] The deformation of snow in terms of a structural mechanism. [Union Géodésique et Géophysique Internationale. Association Internationale des Sciences Hydrologiques. Commission des Neiges et Glaces.] Symposium. Mécanique de la neige. Actes du colloque de Grindelwald, avril 1974, p. 145-54. (IAHS-AISH Publication No. I 14.$)$

Underwood, E. E. 1970. Quantitative stereology. Reading, Mass., Addison-Wesley Publishing Co. 